\title{
Влияние степени нитридизации сапфира и обогащения алюминием зародышевого слоя на структурные свойства слоев AIN
}

\author{
(C) Т.В. Малин ${ }^{1}$, Д.С. Милахин ${ }^{1}$, В.Г. Мансуров ${ }^{1}$, Ю.Г. Галицын ${ }^{1}$, А.С. Кожухов ${ }^{1}$, В.В. Ратников ${ }^{2}$, \\ А.Н. Смирнов ${ }^{2}$, В.Ю. Давыдов ${ }^{2}$, К.С. Журавлев ${ }^{1,3}$ \\ ${ }^{1}$ Институт фризики полупроводников им. А.В. Ржанова Сибирского отделения Российской академии наук, \\ 630090 Новосибирск, Россия \\ ${ }^{2}$ Физико-технический институт им. А.Ф.Иоффе Российской академии наук, \\ 194021 Санкт-Петербург, Россия \\ ${ }^{3}$ Новосибирский государственный университет, \\ 630090 Новосибирск, Россия \\ E-mail: mal-tv@isp,nsc.ru
}

(Получена 4 апреля 2017 г. Принята к печати 10 апреля 2017 г.)

Изучено влияние атомарного алюминия, нанесенного на подложку сапфира, нитридизованную в разной степени, на качество слоев AlN, выращенных методом аммиачной молекулярно-лучевой эпитаксии. Нитридизация сапфира с формированием на его поверхности $\sim 1$ монослоя AlN обеспечивает рост слоев с более гладкой поверхностью и лучшего кристаллического качества по сравнению нитридизацией сапфира, приводящей к формированию нитридизованного слоя AlN толщиной $\sim 2$ монослоя. Изменение времени экспонирования нитридизованных подложек в потоке атомарного алюминия существенного влияния на параметры последующих слоев AlN не оказывает.

DOI: $10.21883 /$ FTP.2018.06.45930.8600

\section{1. Введение}

Нитриды элементов III группы являются прямозонными материалами с шириной запрещенной зоны от 3.4 до 6.2 эВ [1], они обладают высокой теплопроводностью, благодаря чему рассматриваются как перспективные материалы оптоэлектроники и сильноточной высокотемпературной электроники. Приборные гетероструктуры на основе $\mathrm{A}^{\mathrm{III}}$-нитридов получают эпитаксиальными методами, такими как газофазная эпитаксия из металлоорганических соединений (МОСГФЭ), молекулярно-лучевая эпитаксия из аммиака ( $\mathrm{NH}_{3}$-МЛЭ) и активированного плазмой азота (ПА-МЛЭ). На сегодняшний день наиболее доступной и широко используемой подложкой для эпитаксиального роста $\mathrm{A}^{\mathrm{III}}$-нитридов является сапфир.

Рост $A^{\mathrm{III}}$-нитридов на подложке из сапфира связан с рядом технологических трудностей ввиду большого рассогласования параметров кристаллической решетки подложки сапфира $\left(a_{s}=4.76 \AA\right)$ и выращиваемой пленки $\mathrm{AlN} / \mathrm{GaN}\left(a_{f}=3.11 \AA / 3.18 \AA\right)$, равного $\left(a_{s}-a_{f}\right) / a_{s}=53.1-49.7 \%$, а также коэффициентов температурного расширения сапфира $\left(5.0 \cdot 10^{-6} \mathrm{~K}^{-1}\right)$ и $\operatorname{AlN}\left(2.9 \cdot 10^{-6} \mathrm{~K}^{-1}\right)$ [2,3]. Во время становления эпитаксиальных технологий была развита последовательность ростовых технологических операций, обеспечивающая согласование параметров решеток сапфира и последующих слоев $\mathrm{AlGaN}$. В качестве обязательного начального этапа роста была определена нитридизация сапфира, которая заключается в экспонировании разогретой сапфировой подложки в потоке активного азота [4-14]. В ходе нитридизации на поверхности сапфира формируется слой $\mathrm{AlN}$ с элементарной ячейкой, развернутой на $30^{\circ}$ относительно элементарной ячейки сапфира. Этот слой
$\mathrm{AlN}$ располагается поверх гексагональной квазиячейки сапфира, имеющей в вершинах 3 атома $\mathrm{Al}$ и 3 октаэдрические пустоты с эффективным размером ячейки $2.75 \AA$, что уменьшает рассогласование параметров решеток сапфира и $\mathrm{AlN}$ до $13 \%$ [2,3].

Процесс нитридизации является сложным и проходит в несколько этапов. По данным работы [10], в начале процесса нитридизации на поверхности сапфира появляются зародыши AlN, затем зародыши разрастаются и образуют сплошное покрытие AIN. Дальнейшая нитридизация сапфира приводит к увеличению толщины слоя AlN. В результате нитридизованный слой состоит из разориентированных друг относительно друга кристаллических доменов $\mathrm{AlN}$ и характеризуется развитой поверхностью [10]. Кинетика формирования AlN при нитридизации исследовалась достаточно активно различными методами. В работах [4-8] измерялась концентрация связанного азота методами рентгеновской фотоэлектронной спектроскопии (РФЭС) и электронной оже-спектроскопии (ОЭС). Авторы работы [9] использовали дифракцию быстрых электронов на отражение (ДБЭ), регистрируя интенсивность рефлекса, связанного c AlN, и измеряя значение постоянной кристаллической решетки AlN. В результате этих исследований было установлено, что формирование $\mathrm{AlN}$ в процессе нитридизации проходит две ярко выраженные стадии. Сначала процесс формирования AlN идет с высокой скоростью, а затем замедляется, выходя на насыщение. При быстром формировании AIN на сапфире в процессе нитридизации ширина рефлекса AlN уменьшается $[11,12]$, что может быть связано с увеличением латеральных размеров зародышей вновь образующейся фазы AlN. B дальнейшем происходит нитридизация нижележащих слоев сапфира 
и скорость нитридизации замедляется из-за процесса диффузии активного азота в глубь сапфира сквозь вновь сформированный монослой AlN.

Скорость формирования AlN зависит от условий нитридизации. Авторы работы [4] показали, что в потоке аммиака 1400 норм.мл/мин (sccm) и температуре сапфировой подложки $1050^{\circ} \mathrm{C}$ в установке МОСГФЭ быстрая стадия нитридизации сменяется медленной спустя 3 мин от начала процесса [4]. При температуре подложки $850^{\circ} \mathrm{C}$ в потоке аммиака 20 норм. мл/мин в установке $\mathrm{NH}_{3}$-МЛЭ, по данным работы [9], процесс выходит на насыщение спустя 10 мин от начала нитридизации [9]. Авторы данной работы установили, что при $\mathrm{NH}_{3}$-МЛЭ время быстрой стадии нитридизации варьируется от 120 с до 60 мин при изменении температуры подложки от 500 до $1000^{\circ} \mathrm{C}$ и давления аммиака в диапазоне от 12.5 до 400 норм. мл/мин $[11,12]$. В работе [5] исследован процесс нитридизации в установке ПА-МЛЭ при температуре подложки $400^{\circ} \mathrm{C}$, и оказалось, что процесс формирования сплошного слоя $\mathrm{AlN}$ происходит только через 300 мин после начала нитридизации [5]. Авторы [7] вообще не обнаружили насыщения процесса нитридизации при экспозиции подложки сапфира, нагретой до $700^{\circ} \mathrm{C}$, в потоке ионов азота [7]. Поскольку скорость прохождения этапов нитридизации зависит от условий ее проведения, кристаллическое качество последующих $\mathrm{A}^{\mathrm{III}}$-нитридных слоев зависит от условий нитридизации подложки: температуры, давления аммиака и времени экспозиции в аммиаке [4,9,13-17].

Важно определить, на каком этапе процесса нитридизации можно начинать эпитаксиальный рост. Несмотря на то что условия нитридизации меняют скорость процесса, характер процесса не зависит от условий его проведения, поэтому существенной является степень завершенности процесса $[11,12]$. Обычно исследователи ориентируются на время нитридизации. В работах [4-9] было показано, что существует оптимальное время нитридизации, а при малом и слишком большом временах нитридизации качество слоев ухудшается. Поскольку время - не единственный параметр, определяющий скорость нитридизации, эта задача требует выбора критерия степени завершенности процесса нитридизации, т.е. формирования сплошного слоя AlN. В данной работе в качестве такого критерия предлагается использовать интенсивность дифракционного рефлекса $\operatorname{AlN}(01)$ в на-

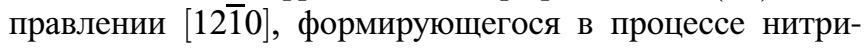
дизации.

Сверхтонкие слои $\mathrm{AlN}$, сформированные в процессе нитридизации, могут быть графеноподобными и неполярными, на что указывают результаты работ [18-19]. Для устойчивого получения металлической полярности рост последующих слоев обычно начинают в избытке металла. Для создания условий обогащения алюминием авторы [20] предложили выращивать слои AIN поверх нитридизованного сапфира методом эпитаксии с повышенной миграцией атомов [20]. Авторы работы [21] сообщают о формировании металлической полярности при нанесении тонкого (30 нм) низкотемпературного $\left(600^{\circ} \mathrm{C}\right)$ слоя AIN (LT-AlN) поверх нитридизованного сапфира, при этом рост слоев $\mathrm{A}^{\mathrm{III}}$-нитридов без нанесения LT-AIN приводит к формированию слоев азотной полярности. В работе [22] показано эффективное подавление инверсионных доменов $\mathrm{N}$-полярности при использовании вставки слоя $\mathrm{AlN}$, выращенного в условиях обогащения Al, при этом подобный эффект отсутствовал при использовании вставки слоя $\mathrm{GaN}$, выращенного в условиях обогащения $\mathrm{Ga}$ [22]. Авторы работы [23], исследуя влияние соотношения потоков $\mathrm{Al} / \mathrm{N}$ на полярность слоев $\mathrm{GaN}$, формируемых методом ПА-МЛЭ, установили, что условия обогащения $\mathrm{Al}$, когда соотношение потоков $\mathrm{Al} / \mathrm{N}=0.6$ и толщина зародышевого слоя $\mathrm{AlN}$ равна $3 \mathrm{Hм}$, являются оптимальными для получения высококачественных слоев металлической полярности. В работах [24,25] сообщается о возможности формирования металлической полярности путем нанесения 2 монослоев алюминия применительно к ПА-МЛЭ. Нанесение $>2$ монослоев алюминия из триметилалюминия на нитридизованную подложку сапфира перед ростом буферного слоя $\mathrm{GaN}$ методом МОСГФЭ применялось в работе [26] с целью изменения полярности растущего слоя. По мере увеличения времени нанесения $\mathrm{N}$-полярность исследуемого слоя $\mathrm{GaN}$ сменялась на смешанную полярность и при времени нанесения $>5$ c формировался слой $\mathrm{GaN}$ металлической полярности [26]. Таким образом, можно заключить, что рост AlN в условиях обогащения $\mathrm{Al}$ позволяет формировать слои металлической полярности. Однако данные о толщине и условиях роста зародышевого слоя $\mathrm{AlN}$, задающего металлическую полярность, сильно разнятся. Также ни в одной из работ не было исследовано влияние условий формирования зародышевого слоя $\mathrm{AlN}$ при различной степени завершенности процесса нитридизации.

В данной работе изучено влияние избытка алюминия, нанесенного на подложку сапфира, нитридизованную в разной степени, на качество слоев AIN.

\section{2. Условия эксперимента}

Исследуемые образцы AIN выращивались на установке фирмы Riber CBE-32(N). В качестве источника алюминия использовались стандартные эффузионные ячейки, в качестве источника активного азота использовался аммиак. Поток аммиака в камеру задавался регулятором потока, работающим в диапазоне $0-400$ норм. мл/мин. Нагрев подложек осуществлялся посредством поглощения излучения нагревателя, для чего на обратную сторону подложки сапфира наносился слой молибдена толщиной 0.4 мкм. Перед экспериментом подложки проходили очистку путем отжига в загрузочной камере при температуре $900^{\circ} \mathrm{C}$ в течение 1 ч. Затем сапфир нитридизовался в потоке аммиака, после чего на нитридизованную подложку сапфира наносился алюминий; на заключительном этапе выращивался слой AlN толщиной 


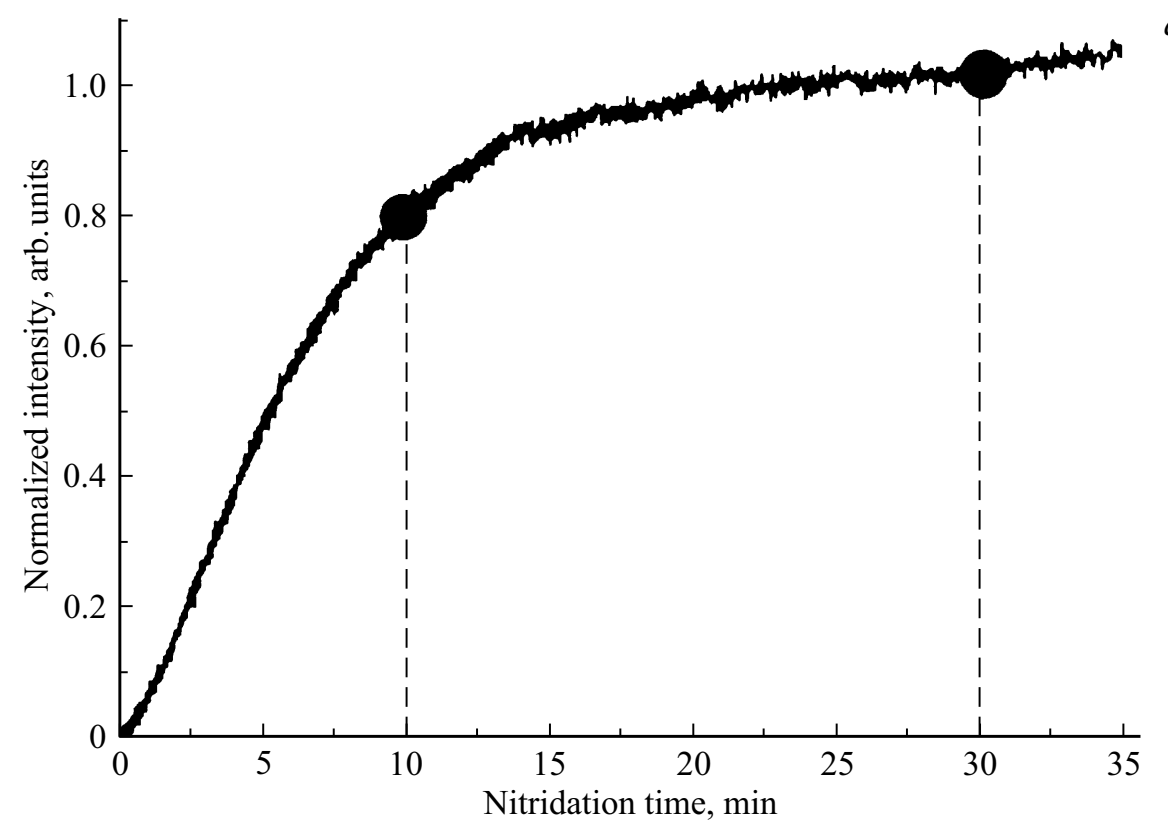

$a$
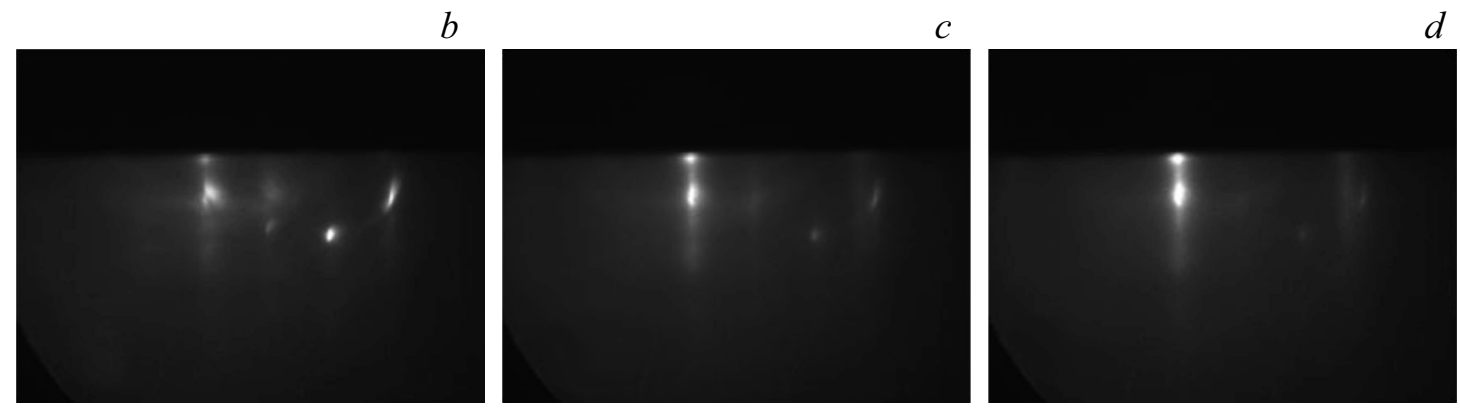

Рис. 1. Кинетическая кривая процесса нитридизации при температуре $840^{\circ} \mathrm{C}$ и потоке аммиака 25 норм. мл/мин $(a)$ и дифракционные картины поверхности исходного сапфира $(b)$ и сапфира после нитридизациив течение 10 мин $(c)$, 30 мин $(d)$.

1 мкм в потоке аммиака 15 норм. мл/мин при температуре подложки $940^{\circ} \mathrm{C}$ со скоростью 0.3 мкм/ч.

Морфология полученных слоев $\mathrm{AlN}$ исследовалась методами ДБЭ и атомно-силовой микроскопии (АСM), кристаллическое качество пленок оценивалось с помощью дифракции рентгеновских лучей (ДРЛ) и комбинационного рассеяния света (КРС). Рентгеноструктурные исследования проводились на трехкристальном рентгеновском спектрометре. Спектры КРС регистрировались в геометрии обратного рассеяния при комнатной температуре на спектрометре Т64000 (производство фирмы Jobin-Yvon Horiba). В качестве источника возбуждения использовался лазер Nd: YAG (длина волны излучения 532 нм).

\section{1. Нитридизация сапфира}

Кинетическая кривая процесса нитридизации при температуре $840^{\circ} \mathrm{C}$ и потоке аммиака 25 норм. мл/мин приведена на рис. 1, $a$. Кривая показывает изменение интенсивности рефлекса от вновь образующейся фазы AIN на поверхности сапфира. Из рис. 1, $a$ видно, что процесс формирования AlN на поверхности сапфира сначала проходит с большой скоростью, затем замедляется и спустя $\sim 30$ мин после начала нитридизации выходит на насыщение. На рис. $1, b-d$ приведены дифракционные картины (ДК) поверхности исходного сапфира и сапфира после нитридизации в течение 10 и 30 мин, соответствующие примерно середине и окончанию участка нитридизации до выхода на насыщение. На ДК после 10-минутной нитридизации (рис. $1, c$ ) видны рефлексы от поверхности сапфира в направлении $[11 \overline{2} 0]$ и слабый рефлекс от вновь образовавшегося AlN. Малая интенсивность рефлекса AIN говорит о малой степени покрытия поверхности и малой толщине слоя $\mathrm{AlN}$. На ДК после 30-минутной нитридизации (рис. 1,d) рефлекс от кристаллической фазы AlN намного ярче, а интенсивность рефлексов от сапфира меньше. Сравнение этих дифракционных картин с ДК из работы [27] (см. рис. 2, 4 из работы [27]), в которой была измерена толщина нитридизованного слоя методом ДРЛ, позволяет заключить, что толщина нитридизованного слоя 


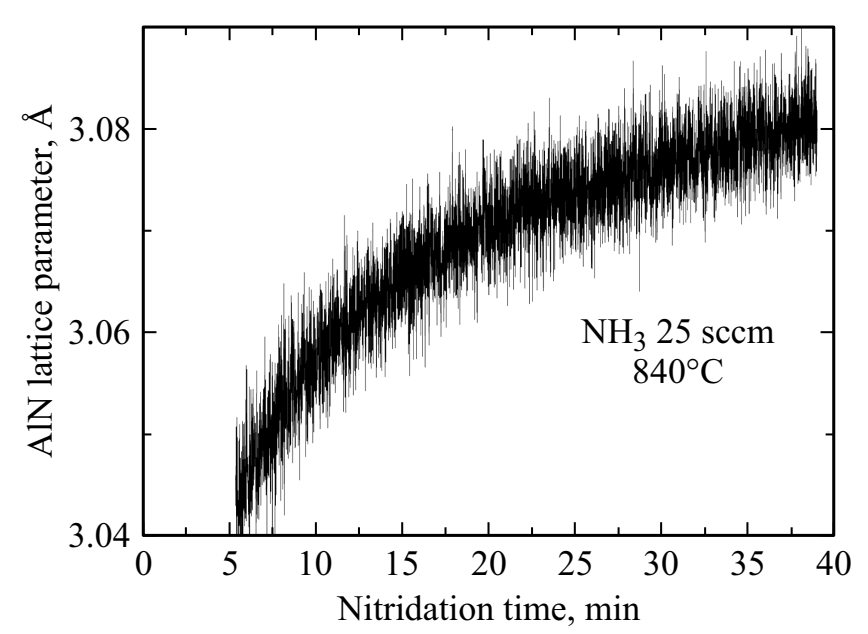

Рис. 2. Изменение параметра $а$ кристаллической решетки AlN в процессе нитридизации при $840^{\circ} \mathrm{C}$ и потоке $\mathrm{NH}_{3} 25$ норм. мл/мин.

составляет $\sim 2 \AA(\sim 1$ монослой, $1 \mathrm{MC})$ и лежит в диапазоне 5-7 $\AA$ ( 2MC) после 10 и 30 мин нитридизации соответственно.

Расстояние между соседними рефлексами AlN (00) и (01) меняется со временем; это означает, что изменяется постоянная решетки AlN. На рис. 2 приведена зависимость параметра решетки $\mathrm{AlN} a$ от времени нитридизации. Параметр решетки AlN меняется от 3.01 до $3.08 \AA$. Следует отметить, что нам не удалось точно измерить параметр решетки $\mathrm{AlN}$ в самом начале процесса нитридизации, поскольку сигнал от AlN не достаточно явный, для того чтобы точно определять его местоположение. Тем не менее полученные нами значения постоянной решетки $\mathrm{AlN}$ не совпадают со значениями из работы [9], в которой было показано, что в процессе нитридизации значение параметра решетки $\mathrm{AlN}$ изменяется от $2.75 \AA$ (соответствует параметру квазиячейки сапфира) до $3.11 \AA$ (соответствует параметру решетки объемного AIN). Возможно, параметр решетки вновь образованного AlN в действительности имеет значение 3.01 , а не $2.75 \AA$, тогда рассогласование между параметрами решетки поверхностной ячейки сапфира и $\mathrm{AlN}$ составляет всего лишь 3-4\%. Отметим, что величина $3.01 \AA$ является фундаментальным значением для чистой поверхности $\mathrm{Al}_{2} \mathrm{O}_{3}$, определенным методом АСМ [28].

Для исследования влияния процесса нитридизации сапфира на морфологию поверхности и кристаллическое качество слоев AlN были выращены слои на исходной (ненитридизованной) и нитридизованной в разной степени подложках сапфира. Разная степень нитридизации (1 МС и $2 \mathrm{MC})$ показана точками на кинетической кривой нитридизации (см. рис. 1,a). Слой $\mathrm{AlN}$, выращенный на ненитридизованной подложке $\mathrm{AlN}$, имеет поликристаллическую структуру (см. рис. $3, a$ ), что отличается от результатов, полученных в работах $[4,13-16]$, в которых на ненитридизованном сапфире получались кристаллические слои. Различие можно объяснить ненамеренной нитридизацией сапфира в момент открытия потока аммиака в условиях МОСГФЭ. Подобное возможно при температурах $>950^{\circ} \mathrm{C}$ и потоках аммиака $>100$ норм. мл/мин, когда скорость нитридизации очень высока [16].

\section{2. Нанесение алюминия}

На следующем этапе исследовалось влияние алюминия на кристаллическое качество слоев AlN. Для этого варьировалось время экспонирования подложек сапфира в фиксированном потоке атомарного алюминия, эквивалентном давлению $1.0 \cdot 10^{-7}$ Торр при выключенном потоке аммиака. Нанесение алюминия в течение 30 с соответствует покрытию поверхности сапфира $\mathrm{Al}$ толщиной примерно в $2 \mathrm{MC}$, а 300-секундное нанесение соответствует покрытию толщиной $20 \mathrm{MC}$. Это позволило сформировать зародышевый слой в избытке $\mathrm{Al}$ c соотношением $\mathrm{Al} / \mathrm{N}$, равным 2/1 и 20/1 соответственно. После нанесения алюминия следовал рост слоев $\mathrm{AlN}$, начинающийся с одновременного открытия аммиачного инжектора и заслонок алюминиевых источников при соотношении $\mathrm{Al} / \mathrm{N}$, равном 1/10. В табл. 1 приведены времена нитридизации и экспонирования нитридизованной подложки в потоке алюминия. В дальнейшем для

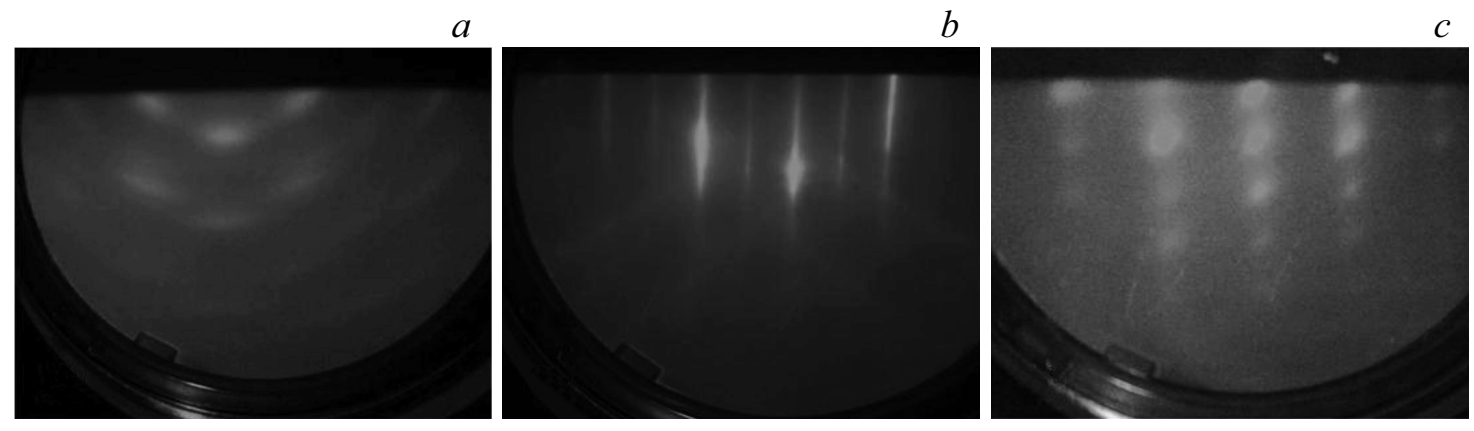

Рис. 3. Дифракционные картины поверхности слоев $\mathrm{AlN}$ в направлении $[11 \overline{2} 0]: a-$ образец, выращенный на ненитридизованной подложке сапфира; $b$ - образцы 10N/0Al, 10N/30Al и 10N/300Al; $c$ - образцы 30N/0A1, 30N/30Al и 30N/300A1. Температура нитридизации $500^{\circ} \mathrm{C}$, поток $\mathrm{NH}_{3} 15$ норм. мл/мин. 

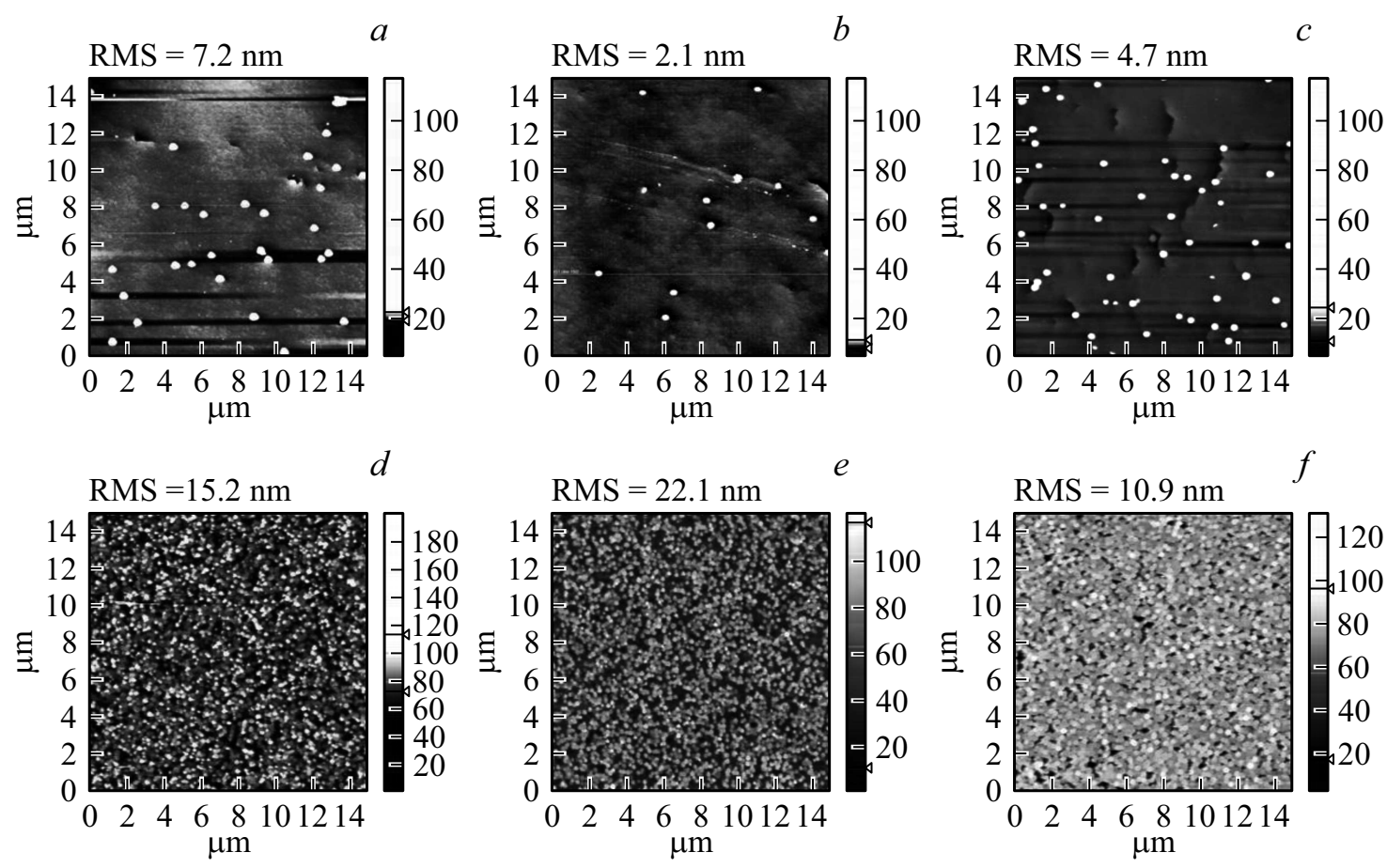

Рис. 4. АСМ-изображения $(15 \times 15$ мкм $)$ исследуемых слоев AlN. Образцы: $a-10 \mathrm{~N} / 0 \mathrm{Al}, b-10 \mathrm{~N} / 30 \mathrm{Al}, c-10 \mathrm{~N} / 300 \mathrm{Al}$. $d-30 \mathrm{~N} / 0 \mathrm{Al}, e-30 \mathrm{~N} / 30 \mathrm{Al}, f-30 \mathrm{~N} / 300 \mathrm{Al}$.

Таблица 1. Обозначения образцов AlN с разными временами нитридизации и зарождения

\begin{tabular}{l|c|c|c|c}
\hline \multicolumn{2}{c|}{$\begin{array}{c}\text { Время нанесения } \\
\text { атомарного алюминия }\end{array}$} & $0 \mathrm{c}$ & $30 \mathrm{c}$ & $300 \mathrm{c}$ \\
\multicolumn{2}{c}{$\longrightarrow$} & & & \\
\hline Время & $10 \mathrm{Mин}$ & $10 \mathrm{~N} / 0 \mathrm{Al}$ & $10 \mathrm{~N} / 30 \mathrm{Al}$ & $10 \mathrm{~N} / 300 \mathrm{Al}$ \\
нитридизации & $30 \mathrm{мин}$ & $30 \mathrm{~N} / 0 \mathrm{Al}$ & $30 \mathrm{~N} / 30 \mathrm{Al}$ & $30 \mathrm{~N} / 300 \mathrm{Al}$
\end{tabular}

обозначения образцов мы будем указывать через косую черту время нитридизации (в минутах) и время экспонирования в потоке алюминия (в секундах). Два образца (10N/0Al и 30N/0Al) были выращены без экспонирования нитридизованной подложки в потоке алюминия.

\section{3. Результаты исследования слоев AIN и обсуждение}

Морфология поверхности полученных слоев AlN оценивалась методами ДБЭ и АСМ. На рис. 3 представлены ДК от поверхности слоев $\mathrm{AlN}$, полученных при температуре $500^{\circ} \mathrm{C}$ и потоке аммиака 15 норм. мл/мин. Образцы 10N/0Al, 10N/30Al и 10N/300Al характеризуются ДК с узкими рефлексами, что характерно для гладкой поверхности (двумерная ДК). Наличие ярких рефлексов $(2 \times 2)$ поверхностной реконструкции свидетельствует о металлической полярности слоев AIN [29-31]. Изменение времени экспонирования слоев в потоке алюминия никак не сказывалось на виде ДК. ДК от образцов 30N/0Al, 30N/30Al и 30N/300Al имеют признаки дифракции в режиме пропускания (трехмерная ДК), характерной для поверхности с развитой морфологией, на ней отсутствуют рефлексы реконструкции. Развитие рельефа поверхности может быть связано с бо́льшим количеством разориентированных друг относительно друга и отклоненных от нормали доменов AIN и наличием большего числа инверсионных доменов, которые растут быстрее колонн с металлической полярностью [32]. Отсутствие реконструкции поверхности $(2 \times 2)$ также объясняется инверсионными доменами, поскольку поверхность слоев азотной полярности не образует реконструкции $(2 \times 2)$ при $500^{\circ} \mathrm{C}$ в потоке аммиака [29-31]. Увеличение ширины рефлексов от поверхностей AlN образцов 30N/0Al, 30N/30Al, 30N/300Al указывает на высокую степень зернистости поверхности. Изменение времени экспозиции в потоке алюминия не оказывало влияния на характер ДК.

Данные по морфологии поверхности, полученные методом ДБЭ, хорошо согласуются с данными, полученными методом АСМ. На рис. 4 приведены АСМ-изображения участка поверхности $15 \times 15$ мкм исследуемых слоев AlN. Поверхность всех образцов с толщиной нитридизованного слоя $1 \mathrm{MC}$ - гладкая. Среднеквадратичные значения шероховатости поверхности (RMS) небольшие, 2.1-7.2 нм, плотность инверсионных доменов сравнительно невелика, 0.07-0.4 мкм $^{-2}$. Наименьшая плотность инверсионных доменов наблюдается на образце 10N/30Al. Данный образец также 
характеризуется наименьшим значением шероховатости $\mathrm{RMS}=2.1$ нм. Поверхность образцов AIN с толщиной нитридизованного слоя $2 \mathrm{MC}$, напротив, имеет высокую плотность инверсионных доменов, 17-25 мкм ${ }^{-2}$, высота которых составляет $\sim(70-90)$ нм, и характеризуется развитой морфологией; в этом случае $\mathrm{RMS}=10.9-22.1$ нм. Наибольшую шероховатость имеет образец $30 \mathrm{~N} / 30 \mathrm{Al}, \mathrm{RMS}=22.1 \mathrm{HM}$, однако при этом на нем наблюдается наименьшая плотностью инверсионных доменов $\left(\sim 18\right.$ мкм $\left.^{-2}\right)$. Наблюдаемая особенность может быть следствием более высокой плотности инверсионных доменов для образцов 30N/0A1 и 30N/300A. Стоящие вплотную инверсионные домены приводят к уменьшению расчетного значения RMS, поскольку их поверхность лишена глубоких провалов до областей поверхности AlN с металлической полярностью. Из приведенных данных видно, что для образцов с толщиной нитридизованного слоя $2 \mathrm{MC}$ оптимальным является время экспозиции в потоке атомарного Al 30 с. Несмотря на то что значение RMS для данного образца выше, этот образец обладает наименьшей плотностью инверсионных доменов $\left(17\right.$ мкм $\left.^{-2}\right)$.

Структурные свойства слоев AlN исследовались методами дифракции рентгеновских лучей (ДРЛ) и комбинационного рассеяния света (КРС). Кристаллическое качество слоев оценивалось из измерений полной ширины на половине высоты пика (FWHM) рентгеновских рефлексов и значений FWHM полосы $E_{2}$ (high) в спектрах КРС. Измерялись FWHM симметричного рефлекса 0002, отражающего микроразориентации плоскостей $\{0001\}$ из-за дефектов, в основном вертикальных винтовых дислокаций (плотностью $\rho_{\text {screw }}$ ), и полуширина кососимметричного рефлекса $10 \overline{1} 5$ (skewgeometry), которая чувствительна к смещениям, в частности из-за наличия вертикальных краевых и смешанного типа дислокаций (плотностью $\rho_{\text {edge }}$ ). Плотности дислокаций рассчитывались по формуле для хаотически распределенных дислокаций [33]. Полученные результаты измерений ДРЛ приведены в табл. 2. Из табл. 2 видно, что наименьшие FWHM симметричного и кососимметричного рефлексов и, как следствие, рассчитанные величины плотности вертикальных винтовых дислокаций и дислокаций смешанного типа относятся к слоям с 30-секундным экспонированием в потоке $\mathrm{Al}$ для обоих времен нитридизации. Кривые качания образца 30N/300Al несимметричны, из-за чего определить значения FWHM для данного образца не удалось. Подобная ситуация характерна для слоев с двумя ярко выраженными типами разориентации растущих доменов. По данным ДРЛ, наименьшими значениями FWHM для симметричного и кососимметричного рефлексов обладает образец 10N/30A1. Спектры КРС приведены на рис. 5. Наиболее совершенной кристаллической структурой обладают образцы 30N/300Al, 30N/30Al, 10N/30Al, для которых значение FWHM полосы симметрии $E_{2}$ (high) находится в пределах $4.1-4.3 \mathrm{~cm}^{-1}$ (табл. 3). Кроме этого, следует отметить, что в спектрах образцов 30N/0Al и 30N/30Al наблюдается дополнительная особенность в
Таблица 2. Данные рентгеноструктурного исследования слоев AIN

\begin{tabular}{|c|c|c|c|c|c|}
\hline & $\begin{array}{r}\text { Вр } \\
\text { атома }\end{array}$ & $\begin{array}{l}\text { мя нанесения } \\
\text { ного алюминия } \\
\longrightarrow\end{array}$ & $0 \mathrm{c}$ & $30 \mathrm{c}$ & $300 \mathrm{c}$ \\
\hline 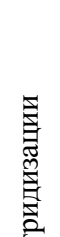 & $\begin{array}{c}10 \\
\text { мин }\end{array}$ & $\begin{array}{c}R, \mathrm{M} \\
\sigma_{a}, \text { ГПа } \\
\text { FWHM }(0002), \text { угл. с } \\
\rho_{\text {screw }}, 10^{9} \mathrm{~cm}^{-2} \\
\text { FWHM }(10 \overline{1} 5), \text { угл. с } \\
\rho_{\text {edge }}, 10^{9} \mathrm{~cm}^{-2}\end{array}$ & $\begin{array}{c}+31.9 \\
+0.53 \\
505 \\
0.55 \\
991 \\
4.91\end{array}$ & $\begin{array}{l}+27.3 \\
+0.62 \\
422 \\
0.39 \\
874 \\
3.82\end{array}$ & $\begin{array}{c}+32.7 \\
+0.52 \\
588 \\
0.75 \\
1010 \\
5.1\end{array}$ \\
\hline 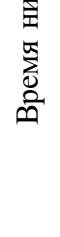 & $\begin{array}{c}30 \\
\text { мин }\end{array}$ & $\begin{array}{c}R, \mathrm{M} \\
\sigma_{a}, \text { ГПа } \\
\text { FWHМ }(0002), \text { угл. с } \\
\rho_{\text {screw }}, 10^{9} \mathrm{~cm}^{-2} \\
\text { FWHM }(10 \overline{1} 5), \text { угл. с } \\
\rho_{\text {edge }}, 10^{9} \mathrm{~cm}^{-2}\end{array}$ & $\begin{array}{c}+75.0 \\
+0.23 \\
1029 \\
2.3 \\
1507 \\
11.3\end{array}$ & $\begin{array}{l}+67.0 \\
+0.25 \\
656 \\
0.94 \\
832 \\
3.5\end{array}$ & $\begin{array}{c}+34.7 \\
+0.59 \\
803 \\
1.4 \\
961 \\
4.6\end{array}$ \\
\hline
\end{tabular}

Таблица 3. Результаты исследований образцов методом КРС

\begin{tabular}{|c|c|c|c|c|c|}
\hline \multicolumn{3}{|c|}{$\begin{array}{c}\text { Время нанесения } \\
\text { атомарного алюминия } \\
\longrightarrow\end{array}$} & $0 \mathrm{c}$ & $30 \mathrm{c}$ & $300 \mathrm{c}$ \\
\hline 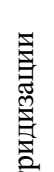 & $\begin{array}{c}10 \\
\text { мин }\end{array}$ & $\begin{array}{l}\Delta \omega, \mathrm{cm}^{-1} \\
\sigma_{a}, \Gamma \Pi \mathrm{a} \\
\text { FWHM } \\
E_{2}(\text { high }), \mathrm{cm}^{-1}\end{array}$ & $\begin{array}{c}-3.0 \\
+0.48 \\
4.4\end{array}$ & $\begin{array}{r}-2.9 \\
+0.46 \\
4.3\end{array}$ & $\begin{array}{c}-2.5 \\
+0.40 \\
4.8\end{array}$ \\
\hline 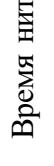 & $\begin{array}{c}30 \\
\text { мин }\end{array}$ & $\begin{array}{l}\Delta \omega, \mathrm{cm}^{-1} \\
\sigma_{a}, \text { ГПа } \\
\text { FWHM } \\
E_{2}(\text { high }), \mathrm{cm}^{-1}\end{array}$ & $\begin{array}{c}-0.2 \\
+0.03 \\
5.1\end{array}$ & $\begin{array}{c}-0.6 \\
+0.1 \\
4.2\end{array}$ & $\begin{array}{c}+0.5 \\
-0.08 \\
4.1\end{array}$ \\
\hline
\end{tabular}

районе $\sim(613-614) \mathrm{cm}^{-1}$, которая может быть связана c запрещенной в этой геометрии рассеяния фононной линией симметрии $A_{1}(\mathrm{TO})$. Появление этой линии, вероятнее всего, указывает на небольшое отклонение гексагональной оси слоев AIN от нормали к поверхности образца в направлении, близком к $10 \overline{1} 2$ [34].

Кроме того, методом ДРЛ измерялся радиус изгиба $R$, который дает информацию об однородных латеральных биаксиальных напряжениях $\left(\sigma_{a}\right)$ сжатия $(R<0)$ или растяжения $(R>0)$. Величины $\sigma_{a}$ рассчитывались по формуле Стоуни [35], в расчетах учитывался изгиб исходных подложек сапфира. Все образцы с толщиной нитридизованного слоя $1 \mathrm{MC}$ в независимости от времени нанесения атомарного Al были вогнутыми со стороны слоя с однородным радиусом изгиба $R \approx-30$ м, что указывает на наличие растягивающих напряжений в слоях, и значением $\sigma_{a}$ в среднем около +0.55 ГПа. Растягивающие напряжения в пленках с толщиной нитридизованного слоя $2 \mathrm{MC}$ в 2 раза меньше, чем в образцах с толщиной нитридизованного слоя $1 \mathrm{MC}$, за исключением образца 30N/300Al с 5-минутным экспонированием в потоке 

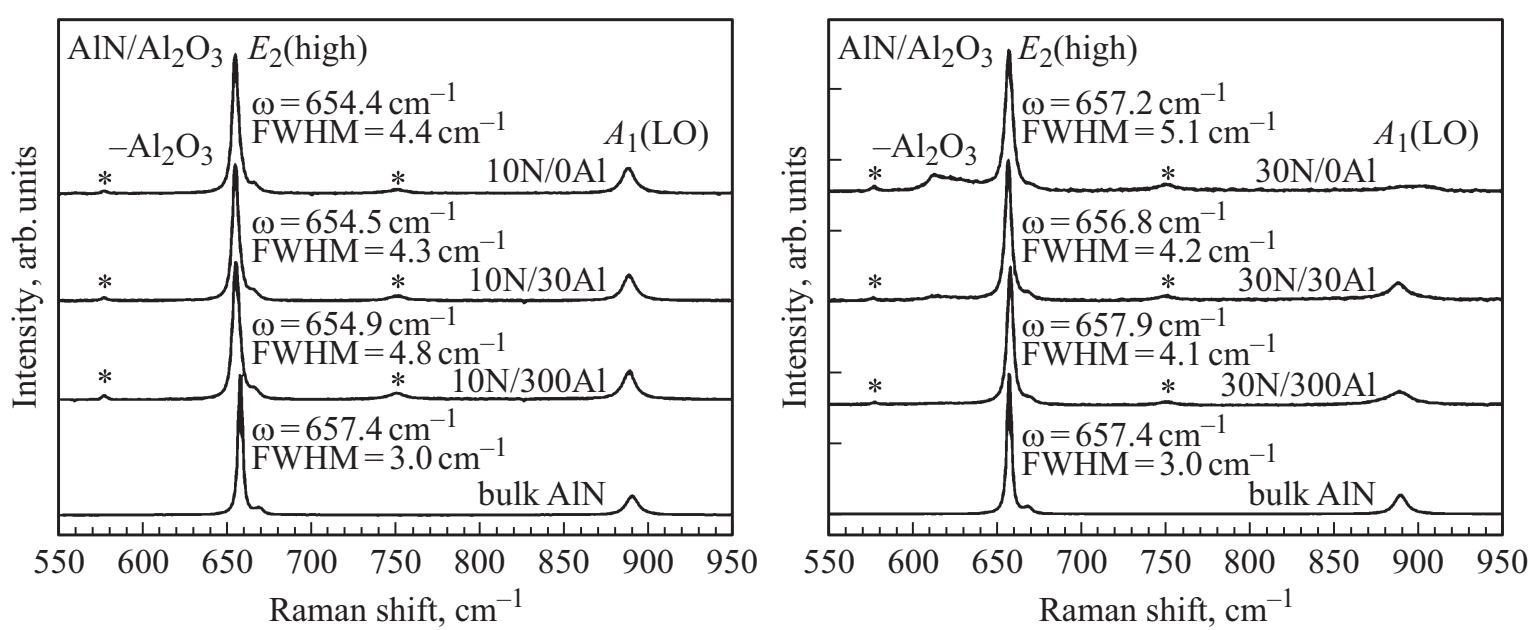

Рис. 5. Поляризованные спектры КРС исследованных слоев AlN. $T=300 \mathrm{~K}$, возбуждение с длиной волны 532 нм, геометрия рассеяния $z(x x) z$ ( $z$ совпадает с направлением роста слоя AlN).

$\mathrm{Al}$, для него $\sigma_{a}=+0.59$ ГПа. Аналогичные результаты были получены методом КРС (табл. 3). Величина $\Delta \omega$ в таблице отражает разность между измеренной частотой колебаний фононов симметрии $E_{2}($ high) и значением $657.4 \mathrm{~cm}^{-1}$ для ненапряженного AlN, полученным в работе [36]. Отрицательная разность частот означает, что исследованные пленки AlN растянуты. Напряжения в плоскости слоев $\mathrm{AlN}$ определялись по формуле $\sigma_{a}=\Delta \omega / K$, где $K=-6.3$ [36]. Все образцы с толщиной нитридизованного слоя $\sim 1 \mathrm{MC}$ в независимости от времени нанесения атомарного алюминия, характеризуются значением $\sigma_{a}$ в среднем около +0.45 ГПа. Растягивающие напряжения в пленках с толщиной нитридизованного слоя $\sim 2 \mathrm{MC}$ практически отсутствуют. Для образца 30N/300Al с 5-минутным экспонированием в потоке $\mathrm{Al}$ напряжения имеют характер сжатия, для него $\sigma_{a}=+0.08$ ГПа. Выявленные тенденции изменения напряжений в слоях AlN по данным ДРЛ и КРC хорошо согласуются.

Обнаруженные растягивающие напряжения в слоях AlN на $\mathrm{Al}_{2} \mathrm{O}_{3}$ представляют собой нетривиальный peзультат, поскольку различия объемных параметров решеток $\mathrm{Al}_{2} \mathrm{O}_{3}$ и $\mathrm{AlN}$ должны приводить к возникновению сжимающих напряжений в слоях AlN. Объяснить наличие растягивающих напряжений в слоях AlN можно с помощью механизма, предложенного в работе [37], предположив, что данный механизм будет превалировать над сжимающими напряжениями, продиктованными параметром решетки подложки. В своей работе автор говорит об образовании внутренних напряжений, которые вводятся в слой AlN во время роста в процессе сращивания отдельных островков. Уменьшение или отсутствие растягивающих напряжений в слоях AlN с толщиной нитридизованного слоя $\sim 2 \mathrm{MC}$ может являться следствием компенсации растягивающих напряжений, возникающих при сращивании островков AlN, сжимающими напряжениями, обусловленными различием параметров решеток $\mathrm{AlN}$ и $\mathrm{Al}_{2} \mathrm{O}_{3}$.

\section{4. Заключение}

В работе установлено, что нитридизация сапфира с формированием на его поверхности $\sim 1 \mathrm{MC}$ AlN обеспечивает последующий рост слоев AlN с более гладкой поверхностью и лучшим кристаллическим качеством по сравнению нитридизацией сапфира, формирующей более толстый ( $2 \mathrm{MC})$ слой AlN. Возможно, это связано с тем, что увеличение толщины нитридизованного слоя приводит к формированию большего числа отклоненных зародышей AlN и увеличению количества инверсионных доменов. Экспонирование нитридизованных подложек в потоке атомарного алюминия оказывает влияние только на структурные параметры слоев AlN. При времени экспонирования, соответствующем покрытию нитридизованной поверхности сапфира атомарным алюминием в $\sim 2 \mathrm{MC}$, FWHM рентгеновских рефлексов уменьшаются по сравнению с образцами без нанесения алюминия, а при дальнейшем увеличении времени экспонирования кристаллическое качество пленок ухудшается.

Таким образом, нитридизация, формирующая $\sim 1 \mathrm{MC}$ кристаллической фазы AlN, и последующее экспонирование в потоке атомарного $\mathrm{Al}$, проводящее к покрытию нитридизованной поверхности сапфира $\sim 2 \mathrm{MC}$ атомарного $\mathrm{Al}$, позволяют выращивать слои $\mathrm{AlN}$ методом аммиачной МЛЭ с наилучшими параметрами.

Исследование выполнено при финансовой поддержке РФФИ (17-02-00947, 16-32-00773, 16-02-00702).

\section{Список литературы}

[1] S. Strite, H. Morkoc. J. Vac. Sci. Technol., 10, 1237 (1992).

[2] T. Yamaguchi, T. Araki, Y. Saito, K. Kano, H. Kanazawa, Y. Nanishi, N. Teraguchi, A. Suzuki. J. Cryst. Growth, 237-239 (2), 993 (1994).

[3] K. Masu, Y. Nakamura, T. Yamazaki, T. Shibata, M. Takahashi, K. Tsubouchi. Jpn. J. Appl. Phys., 34 (6B), 760 (1995). 
[4] K. Uchida, A. Watanabe, F. Yano, M. Kouguchi, T. Tanaka, S. Minagawa. J. Appl. Phys., 79 (7), 3487 (1996).

[5] Ch. Heinlein, J. Grepstad, T. Berge, H. Riechert. Appl. Phys. Lett., 71 (3), 341 (1997).

[6] A. Georgakilas, S. Mikroulis, V. Cimalla, M. Zervos, A. Kostopoulos, Ph. Komninou, Th. Kehagias, Th. Karakostas. Phys. Status Solidi A, 188 (2), 567 (2001).

[7] F. Dwikusuma, T.F. Kuech. J. Appl. Phys., 94 (9), 5656 (2003).

[8] B. Agnarsson, M. Göthelid, S. Olafsson, H.P. Gislason, U.O. Karlsson. J. Appl. Phys., 101, 013519 (2007).

[9] N. Grandjean, J. Massies, M. Leroux. J. Appl. Phys., 69, 2071 (1996).

[10] M. Yeadon, M.T. Marshall, F. Hamdani, S. Pekin, H. Morkoc, J. Murray Gibson. J. Appl. Phys., 83 (5), 2847 (1998).

[11] T. Malin, V. Mansurov, Y. Galitsyn, K. Zhuravlev. Phys. Status Solidi C, 11 (3-4), 613 (2014).

[12] T. Malin, V. Mansurov, Y. Galitsyn, K. Zhuravlev. Phys. Status Solidi C, 12 (4-5), 443 (2015).

[13] Y. Wu, A. Hanlon, J.F. Kaeding, R. Sharma, P.T. Fini, S. Nakamura, J.S. Speck. Appl. Phys. Lett., 84 (6), 912 (2004).

[14] W.-G. Hu, Ch.-M. Jiao, H.-Y. Wei, P.-F. Zhang, T.T. Kang, R.-Q. Zhang, X.-L. Liu. Chin. Phys. Lett., 25 (12), 4364 (2008).

[15] K.S. Kim, K.Y. Lim, H.J. Lee. Semicond. Sci. Technol., 14, 557 (1999).

[16] L.-C. Le, D.-G. Zhao, L.-L. Wu, Y. Deng, D.-S. Jiang, J.-J. Zhu, Z.-S. Liu, H. Wang, S.-M. Zhang, B.-S. Zhang, H. Yang, Chin. Phys. B, 20 (12), 127306 (2011).

[17] W. Kim, M. Yeadon, A.E. Botchkarev, S.N. Mohammad, J.M. Gibson, H. Morkoc. J. Vac. Sci. Technol. B, 15 (4), 921 (1997).

[18] C.L. Freeman, F. Claeyssens, N.L. Allan. Phys. Rev. Lett., 96, 066102 (2006).

[19] C.J.F. Solano, A. Costales, E. Francisco, A.M. Pendas, M.A. Blanco, K.-C. Lau, H. He, R. Pandey. J. Phys. Chem. C, 112 (17), 6667 (2008).

[20] A. Yoshikawa, K. Takahashi. Phys. Status Solidi A, 188 (2), 625 (2001).

[21] F. Liu, R. Collazo, S. Mita, Z. Sitar, G. Duscher, S.J. Pennycook. J. Appl. Phys. Lett., 91, 203115 (2007).

[22] J. Ohta, H. Fujioka, M. Oshima, K. Fujiwara, A. Ishii. Appl. Phys. Lett., 83 (15), 3075 (2003).

[23] S.K. Davidsson, J.F. Falth, X.Y. Liu, H. Zirath, T.G. Andersson. J. Appl. Phys., 98, 016109 (2005).

[24] K. Xu, N. Yano, A.W. Jia, A. Yoshikawa, K. Takahashi. J. Cryst. Growth, 237-239 (2), 1003 (2002).

[25] Y.S. Park, H.S. Lee, J.H. Na, H.J. Kim, S.M. Si, H.M. Kim, J.E. Oh. J. Appl. Phys., 94, 800 (2003).

[26] D.H. Lim, K. Xu, S. Arima, A. Yoshikawa, K. Takahashi. J. Appl. Phys., 91, 6461 (2002).

[27] Y. Wang, A.S. Ozcan, G. Ozaydin, K.F. Ludwig, jr., A. Bhattacharyya, Th.D. Moustakas, H. Zhou, R.L. Headrick, D.P. Siddons. Phys. Rev. B, 74, 235304 (2006).

[28] J.V. Lauritsen, M.C.R. Jensen, K. Venkataramani, B. Hinnemann, S. Helveg, B.S. Clausen, F. Besenbacher. Phys. Rev. Lett., 103, 076103 (2009).

[29] A.R. Smith, R.M. Feenstra, D.W. Greve, J. Neugebauer, J.E. Nortrhrup. Phys. Rev. Lett., 79, 3934 (1997).

[30] A.R. Smith, R.M. Feenstra, D.W. Greve, M.-S. Shin, M. Skowronski, J. Neugebauer, J.E. Nortrhrup. Surf. Sci., 423, 70 (1999).
[31] N. Kumagai, K. Akiyama, R. Togashi, H. Murakami, M. Takeuchi, T. Kinoshita, K. Takada, Y. Aoyagi, A. Koukitu. J. Cryst. Growth, 305 (2), 366 (2007).

[32] O. Ambacher. J. Phys. D, 31, 2653 (1998).

[33] C.G. Dunn, E.F. Koch. Acta Metall., 5, 548 (1957).

[34] L. Filippidis, H. Siegle, A. Hoffmann, C. Thomsen, K. Karch, F. Bechstedt. Phys. Status Solidi B, 198, 621 (1996).

[35] G.G. Stoney. Proc. Royal Soc. (London), 82 (553), 172 (1909).

[36] T. Prokofyeva, M. Seon, J. Vanbuskirk, M. Holtz. Phys. Rev. B, 63, 125313 (2001).

[37] R.W. Hoffman. Thin Sol. Films, 34, 185 (1976).

Редактор Л.В. Шаронова

\section{Influence of sapphire nitridation level and nucleation layer enrichment with Al on the quality of epitaxial AIN layers}

T.V. Malin ${ }^{1}$, D.S. Milakhin ${ }^{1}$, V.G. Mansurov', Yu.G. Galitsyn ${ }^{1}$, A.S. Kozhuhov' ${ }^{1}$, V.V. Ratnikov' ${ }^{2}$, A.N. Smirnov ${ }^{2}$, V.Yu. Davydov ${ }^{2}$, K.S. Zhuravlev ${ }^{1,3}$

${ }^{1}$ Rzhanov Institute of Semiconductor Physics, Siberian branch of Russian Academy of Sciences, 630090 Novosibirsk, Russia

${ }^{2}$ loffe Institute,

194021 St. Petersburg, Russia

${ }^{3}$ Novosibirsk State University, 630090 Novosibirsk, Russia

Abstract The influence of the additional thin aluminum layer, deposited on the nitridated sapphire surface at different nitridation levels, on the quality of the subsequent epitaxial AlN layers grown by ammonia MBE technique was investigated. Sapphire nitridation process which leads to the AlN 1-monolayer formation on the sapphire surface provides smooth surface and best crystalline perfection compared with sapphire nitridation, resulting in the AlN 2-monolayer formation. Change of the substrates exposition time in atomic aluminum does not effect on the AlN subsequent layers parameters. 